Case report

\title{
Two fatal intoxication cases with imidacloprid: LC/MS analysis
}

\author{
Paula Proença ${ }^{a, *}$, Helena Teixeira ${ }^{\text {a,b }}$, Fernando Castanheira ${ }^{\text {a }}$, \\ João Pinheiro a , Paula V. Monsanto ${ }^{\mathrm{a}}$, Estela P. Marques ${ }^{\mathrm{a}, \mathrm{b}}$, \\ Duarte Nuno Vieira ${ }^{\mathrm{a}, \mathrm{b}}$ \\ ${ }^{a}$ National Institute of Legal Medicine, Delegation of Coimbra, Largo da Sé Nova, 3000-213 Coimbra, Portugal \\ ${ }^{\mathrm{b}}$ Faculty of Medicine, University of Coimbra, Largo da Sé Nova, 3000-213 Coimbra, Portugal
}

Available online 25 May 2005

\begin{abstract}
Imidacloprid [1-(6-chloro-3pyridylmethyl)- $N$-nitroimidazolidin-2-ylideneamine] is a new and potent nitromethylene insecticide with high insecticidal activity at very low application rates. It is the first highly effective insecticide that, like nicotine, acts on the nervous system, causing blockage of postsynaptic nicotinergic acetylcholine receptors. Two fatal cases with this insecticide in two male individuals, of 33 and 66 years old, are presented.

An LC/MS with electrospray method for measuring imidacloprid and its metabolites in post-mortem samples is described. In the chromatographic separation, a reverse-phase column XTerra ${ }^{\mathrm{TM}} \mathrm{MS} \mathrm{C}_{18}(2.1 \mathrm{~mm}$ i.d. $\times 150 \mathrm{~mm}, 5 \mu \mathrm{m})$ was used and the mobile phase composed with acetonitrile and $0.1 \%$ formic acid (15:85), at a $0.25 \mathrm{~mL} / \mathrm{min}$ flow rate. Samples were prepared with a liquid-liquid extraction procedure with dichloromethane.

Calibration curves for imidacloprid in blood and urine samples were linear from 0.2 to $15 \mu \mathrm{g} / \mathrm{mL}$. The mean recovery was $86 \%$ with a coefficient of variation of $\pm 5.9 \%$. The detection limit was $0.002 \mu \mathrm{g} / \mathrm{mL}$. Quantitative results were obtained for all post-mortem matrices available of the two fatal cases: blood, urine, stomach contents, lung, liver and kidney. The imidacloprid blood concentrations found in two-cases were 12.5 and $2.05 \mu \mathrm{g} / \mathrm{mL}$.

The authors validated a method to detect and quantify imidacloprid in post-mortem samples, and to our knowledge for the first time a post-mortem tissue distribution was performed on various samples for this insecticide.
\end{abstract}

(C) 2005 Elsevier Ireland Ltd. All rights reserved.

Keywords: Imidacloprid; Fatal intoxication; LC/MS

\section{Introduction}

Imidacloprid [1-(6-chloro-3-pyridylmethyl)- $N$-nitroimidazolidin-2-ylideneamine] is a member of a relatively new class of insecticidal chemistry, the chloronicotinyl neonicotinoid compounds $[1,2]$. It was introduced into

* Corresponding author. Tel.: +351 239854230; fax: +351239820549 .

E-mail address: paulaproenca@dcinml.mj.pt (P. Proença). commercial use only in the last decade and is increasingly used worldwide. Trade names for Bayer's imidacloprid products in Portugal are Confidor ${ }^{\mathbb{R}}$ and Gaucho $^{\mathbb{R}}$ [3]. It is the most important systemic insecticide and has a wide diversity of uses: in agriculture, on turfs, on pets and for household pests.

Imidacloprid acts on the central nervous system, as an agonist at the nicotinic acetylcholine receptor ( $\mathrm{nAChR}$ ), causing its blockage [4,5]. It is moderately toxic and acute oral $\mathrm{LD}_{50}$ are $450 \mathrm{mg} / \mathrm{kg}$ for male and female rats and 


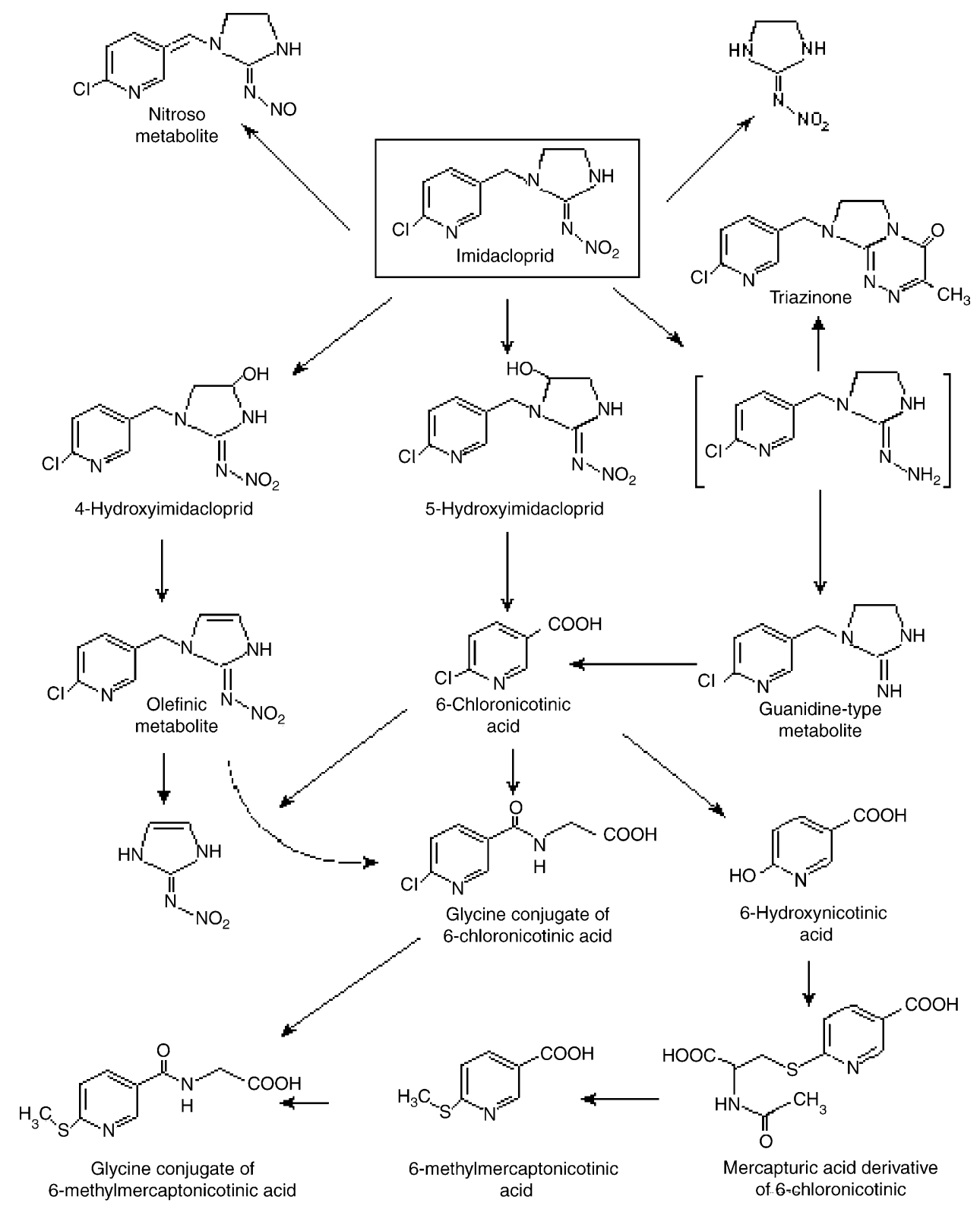

Fig. 1. Metabolic pathways for imidacloprid [6].

$150 \mathrm{mg} / \mathrm{kg}$ for mice [4]. The metabolism of imidacloprid (Fig. 1) has been extensively studied in soils, plants and mammals [5-9]. This insecticide is metabolized by human cytochrome $\mathrm{P}_{450}$ isozymes involving two pathways: (1) imidazolidine hydroxylation and desaturation to give 5-hydroxyimidacloprid and the olefin, respectively, and (2) nitroimine reduction and cleavage to yield the nitrosoimine, guanidine and urea derivatives [5]. Imidacloprid is quickly and almost completely absorbed after ingestion and degraded to 6-chloronicotinic acids, which may be conjugated with glycine and then eliminated or reduced to guanidine. About $70-80 \%$ of an administered dose may be excreted in urine and $20-30 \%$ in faeces [10].

Several methods have been published for the determination by high-performance liquid chromatography of imidacloprid and its main metabolites in soils [11-13], in fruits and vegetables [14-21], in water [13] and even in air [22,23]. No methods have been published for the determination of this insecticide in human samples.

This study reports two fatal cases involving imidacloprid. A liquid chromatography/mass spectrometry (LC/MS) method was developed to detect, confirm and quantify this insecticide in post-mortem samples. 


\section{Case histories}

\subsection{Case 1}

A 33-year-old man was found dead by his wife, at home, lying on the floor near a sofa. She asked for help and called the priest. She did not know who called the emergency paramedics, who verified the death. No signs of violence were found at the death scene, although the family found the death to be suspicious. By all accounts, the decedent had no significant medical history. Further investigations by the prosecutor revealed a suicide letter with the victim's handwriting.

The autopsy performed by local general practitioners was negative, except for an intense smell that they could not specify, and cherry livor mortis. The body showed signs of initial putrefaction. Toxicological analyses were requested.

Pathological examination, performed from frozen samples originally taken for toxicological study (lung, liver, kidney, oesophagus and tongue), showed only severe autolysis.

\subsection{Case 2}

A 66-year-old man was found dead in the supine position in bed at home. On the table in the dining room, there were different documents and other personal objects with written notes about their usefulness, suggesting a suicidal intent. The death certificate stated that the victim had ingested an organophosphorus pesticide. Later, after autopsy and toxicological analysis, the police reported that an empty bottle of Confidor $^{\circledR}$ was found at the scene.

The autopsy performed by local general practitioners showed bloody liquid coming out of the mouth. Mouth, tongue, tonsils and oesophagus revealed red-brown spots compatible with chemical burn. Pulmonary edema and a yellow liver were also found. The stomach contained $150 \mathrm{~mL}$ of a yellow-green liquid with a "white deposit and a fatty substance". Histological findings obtained from poorly preserved samples demonstrated signs of chronic right cardiac insufficiency and deposits of dark granular pigment in lungs.

Samples of blood, urine, stomach contents, liver and kidney were taken for toxicological analysis.

\section{Materials and methods}

\subsection{Chemicals and reagents}

Imidacloprid was obtained from Supelco (Bellefonte, PA, USA), 6-chloronicotinic acid and 5-hydroxyimidacloprid was supplied from Bayer CropScience (Monheim, Germany) and ethirimol (used as internal standard) was obtained from Riedel-de Haën (Seelze, Germany). Each standard compound was dissolved in acetonitrile $(1 \mathrm{mg} /$ $\mathrm{mL})$ and stored at $4{ }^{\circ} \mathrm{C}$. Dichloromethane LiChrosolv ${ }^{\mathbb{B}}$ was purchased from Riedel-de Haën (Seelze, Germany).
Acetonitrile (HPLC-grade) and formic acid (extra pure) were obtained from E. Merck (Darmstadt, Germany). Water was purified by a Milli-Q system obtained from Millipore (Molsheim, France). The mobile phase was filtered through a $0.20 \mu \mathrm{m}$ filter (Schleicher and Schuell) and degassed in an ultrasonic bath for $15 \mathrm{~min}$ just before use. All samples were filtered through a $0.45 \mu \mathrm{m}$ nylon filter (Millipore) before injection into the column.

\subsection{Instrumentation}

The chromatographic system used was a Waters 2695 Alliance System and an XTerra ${ }^{\mathrm{TM}}$ MS $\mathrm{C}_{18}$ reversed-phase column $(2.1 \mathrm{~mm}$ i.d. $\times 150 \mathrm{~mm}, 5 \mu \mathrm{m})$. The mobile phase was composed with acetonitrile and $0.1 \%$ formic acid (15:85), at a flow rate of $0.25 \mathrm{~mL} / \mathrm{min}$. Column temperature was held at $25^{\circ} \mathrm{C}$. The injection volume was $5 \mu \mathrm{L}$.

A Waters 996 photodiode array detector (DAD) was used operated on a $210-400 \mathrm{~nm}$ wavelength scan with a $1.2 \mathrm{~nm}$ resolution. The UV absorbance was measured at $270 \mathrm{~nm}$.

Instrument control, data acquisition and processing were achieved using Waters Empower Software (Milford, MA).

Mass spectrometry (MS) detection was carried out by a Waters ZQ 2000 single quadrupole mass spectrometer with an electrospray ionization (ESI) performed in positive and negative mode. Full-scan spectra were recorded from $\mathrm{m} / \mathrm{z}$, $100-500$, at a scan time of $0.5 \mathrm{~s}$ and an interscan delay of $0.1 \mathrm{~s}$. The mass spectra were represented by centroid mode. The main other instrumental settings were: capillary voltage $3.5 \mathrm{kV}$; cone voltage $30 \mathrm{~V}$; extractor $5 \mathrm{~V}$; ion energy 0.1 ; source temperature $150{ }^{\circ} \mathrm{C}$; desolvation temperature $300{ }^{\circ} \mathrm{C}$; cone gas $\left(\mathrm{N}_{2}\right)$ flow rate $0 \mathrm{~L} / \mathrm{h}$ and desolvation gas $\left(\mathrm{N}_{2}\right)$ flow rate $300 \mathrm{~L} / \mathrm{h}$.

Quantitation employed the selected ion-recording (SIR) mode using the most abundant characteristic ion $[M+\mathrm{H}]^{+}$, $\mathrm{m} / \mathrm{z}, 256$ for imidacloprid and $\mathrm{m} / \mathrm{z}, 210$ for internal standard (ethirimol).

\subsection{Sample preparation}

Control and calibration samples were prepared by spiking drug-free post-mortem blood and urine samples with standard solutions.

Twenty microliters of internal standard (IS) solution (100 $\mu \mathrm{L} / \mathrm{mL}$, ethirimol) was added to $1 \mathrm{~mL} / 1 \mathrm{~g}$ of biological fluids/homogenate tissue and mixed in a vortex for $30 \mathrm{~s}$. Homogenates of tissue samples were prepared by adding $1 \mathrm{~g}$ tissue to $2 \mathrm{~mL}$ distilled water. The liquid-liquid extraction was performed three times with $5 \mathrm{~mL}$ dichloromethane, and the tubes were agitated on a platform shaker for $15 \mathrm{~min}$. After centrifugation at $2000 \times g$ for $10 \mathrm{~min}$ the combined supernatant were evaporated to dryness under a slow stream of nitrogen at $40{ }^{\circ} \mathrm{C}$. The dried extracts were reconstituted with $500 \mu \mathrm{L}$ of mobile phase and an aliquot $(5 \mu \mathrm{L})$ was injected into the LC/MS system. 


\section{Results and discussion}

All specimens were initially subjected to a qualitative analysis. Screening was performed for basic, acidic, and neutral drugs, pesticides and volatiles by standard chromatographic methods. Employed methods included gas chromatography, liquid chromatography and enzyme immunoassay. Blood alcohol results (analysed by a headspace GC/FID technique) were positive in case $1(0.18 \mathrm{~g} / \mathrm{L})$ and negative in case 2. No other drugs or pesticides were found in either post-mortem cases. Imidacloprid was identified in both stomach contents by thin-layer chromatography.

Calibration curves for imidacloprid in blood and urine samples were linear from 0.2 to $15 \mu \mathrm{g} / \mathrm{mL}$ (in blood $y=0.00556 x+0.000918$ with $r^{2}=0.9993$ and in urine $y=0.00138 x+0.000736$ with $r^{2}=0.9978$, seven calibration points, in triplicate).

The detection limit of imidacloprid in blood samples was $0.002 \mu \mathrm{g} / \mathrm{mL}(\mathrm{S} / \mathrm{N}=3)$ and the lower limit of quantification (LOQ, $\mathrm{S} / \mathrm{N}=10$ ) was $0.01 \mu \mathrm{g} / \mathrm{mL}$. Analytical recovery was tested at the concentration levels of 1,5 and $10 \mu \mathrm{g} / \mathrm{mL}$ and was determined by comparing the representative peak areas of imidacloprid extracted from drug-free blood spiked with the peak area of a methanolic standard at the same concentration. The mean recovery was $86 \%$ with a coefficient of variation of $\pm 5.9 \%$. For intra-day and inter-day precision determinations, five replicate analyses were performed at each of the three studied concentrations. Relevant validation data for recovery and precision are presented in Table 1 . The method proved to be precise for imidacloprid, both in terms of intra-day and inter-day analysis, with coefficients of variation $(\mathrm{CV})$ less than $10 \%$.

Imidacloprid and the metabolites, 6-chloronicotinic acid and 5-hydroxyimidacloprid, are polar compounds with high molar absorptivity in the UV-vis region. For this reason, LC with diode array detection was only used for confirmation of their spectra. In Fig. 2, UV spectra of imidacloprid (A) (Rt 8.777), 5-hydroxyimidacloprid (B) (Rt 5.903), 6-chloronicotinic acid (C) (Rt 6.896) and ethirimol internal standard and (D) (Rt 2.603) are represented.

We selected an ESI source to avoid high temperatures, which could produce undesirable degradation processes in pesticides and, as stated by some authors [20], results of imidacloprid were very similar with regard to sensitivity in positive ionization mode when the APCI and ESI sources were used.

Table 1

Validation data of recovery and precision for imidacloprid, in spiked blood samples

\begin{tabular}{rlll}
\hline $\begin{array}{l}\text { Concentration } \\
\text { level }(\mu \mathrm{g} / \mathrm{mL})\end{array}$ & $\begin{array}{l}\text { Recovery } \\
(n=5)(\%)\end{array}$ & $\begin{array}{l}\text { Intra-day } \\
(n=5) \mathrm{CV}(\%)\end{array}$ & $\begin{array}{l}\text { Inter-day } \\
(n=5) \mathrm{CV}(\%)\end{array}$ \\
\hline 1 & 77 & 7.9 & 8.7 \\
5 & 91 & 5.9 & 4.5 \\
15 & 89 & 5.2 & 6.5 \\
\hline
\end{tabular}
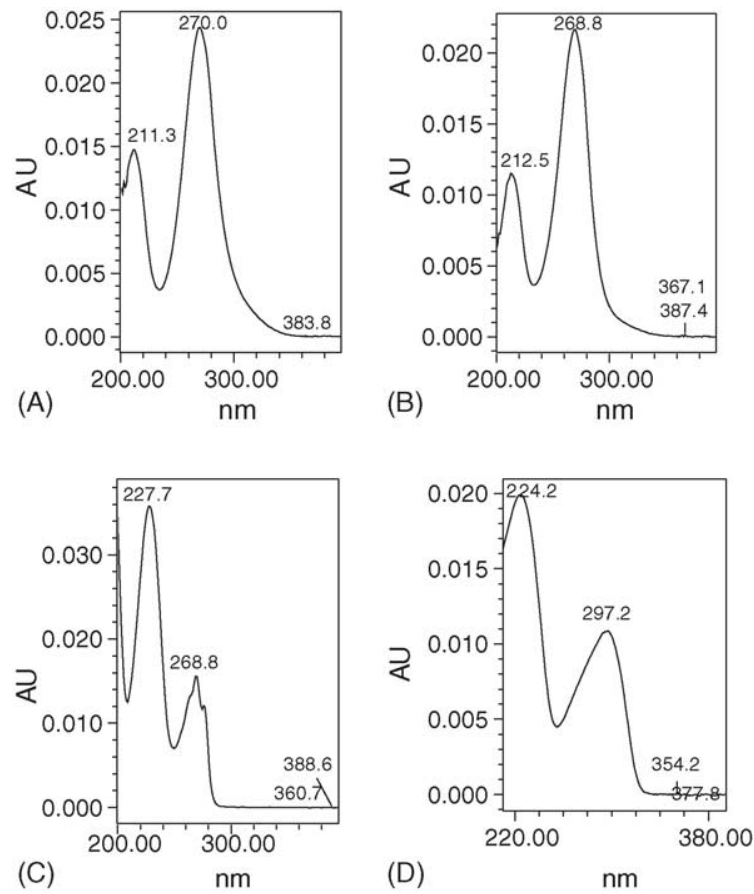

Fig. 2. UV spectra of imidacloprid (A) (Rt 8.777), 5-hydroxyimidacloprid (B) (Rt 5.903), 6-chloronicotinic acid (C) (Rt 6.896) and ethirimol (IS) and (D) (Rt 2.603).

Quantitation employed the selected ion-recording mode using the most abundant characteristic ion, $\mathrm{m} / \mathrm{z} 256$ and the fragment ions, $\mathrm{m} / \mathrm{z}, 209$ and $\mathrm{m} / \mathrm{z}, 175$, corresponding to $\left[M+\mathrm{H}-\mathrm{NO}_{2}\right]^{+}$and $\left[M+\mathrm{H}-\mathrm{NO}_{2}-\mathrm{Cl}\right]^{+}$, respectively, for confirmation. The first fragment, $m / z=209$, is due to the loss of $\mathrm{NO}_{2}$. The second fragment, $m / z=175$, is due to the losses of both $\mathrm{NO}_{2}$ and $\mathrm{Cl}$. Imidacloprid yielded intense protonated and deprotonized molecules ( $\mathrm{m} / \mathrm{z}, 256$ and 254) when ESI was used in positive and negative ionization modes, respectively. SIR mass chromatograms and mass spectrum in scan mode $(\mathrm{m} / \mathrm{z}, 256)$, of imidacloprid detected in blood sample (case 1), and are shown in Fig. 3.

Since the procedure has proved to be sensitive, selective and reproducible, the developed method was applied to the fatal cases presented. The tissue distribution of imidacloprid is presented in Table 2. Imidacloprid was detected in all analysed specimens. The imidacloprid blood concentrations found in the two-cases were 12.5 and $2.05 \mu \mathrm{g} / \mathrm{mL}$. In the tissue samples, the higher imidacloprid concentrations were observed in lung and kidney, apart from liver.

In both reported cases, this insecticide was present in stomach contents, indicating acute imidacloprid intoxication. Stomach contents collected in the described intoxication cases contained high concentrations of imidacloprid and needed to be diluted to the ratio $1: 100$. In case $1,70 \mathrm{mg}$ of imidacloprid was detected in $150 \mathrm{~mL}$ of stomach contents and in case 2, there was $37.1 \mathrm{mg}$ of imidacloprid in $200 \mathrm{~mL}$ of stomach contents. The imidacloprid metabolites, 5-hydroxyimidaclo- 

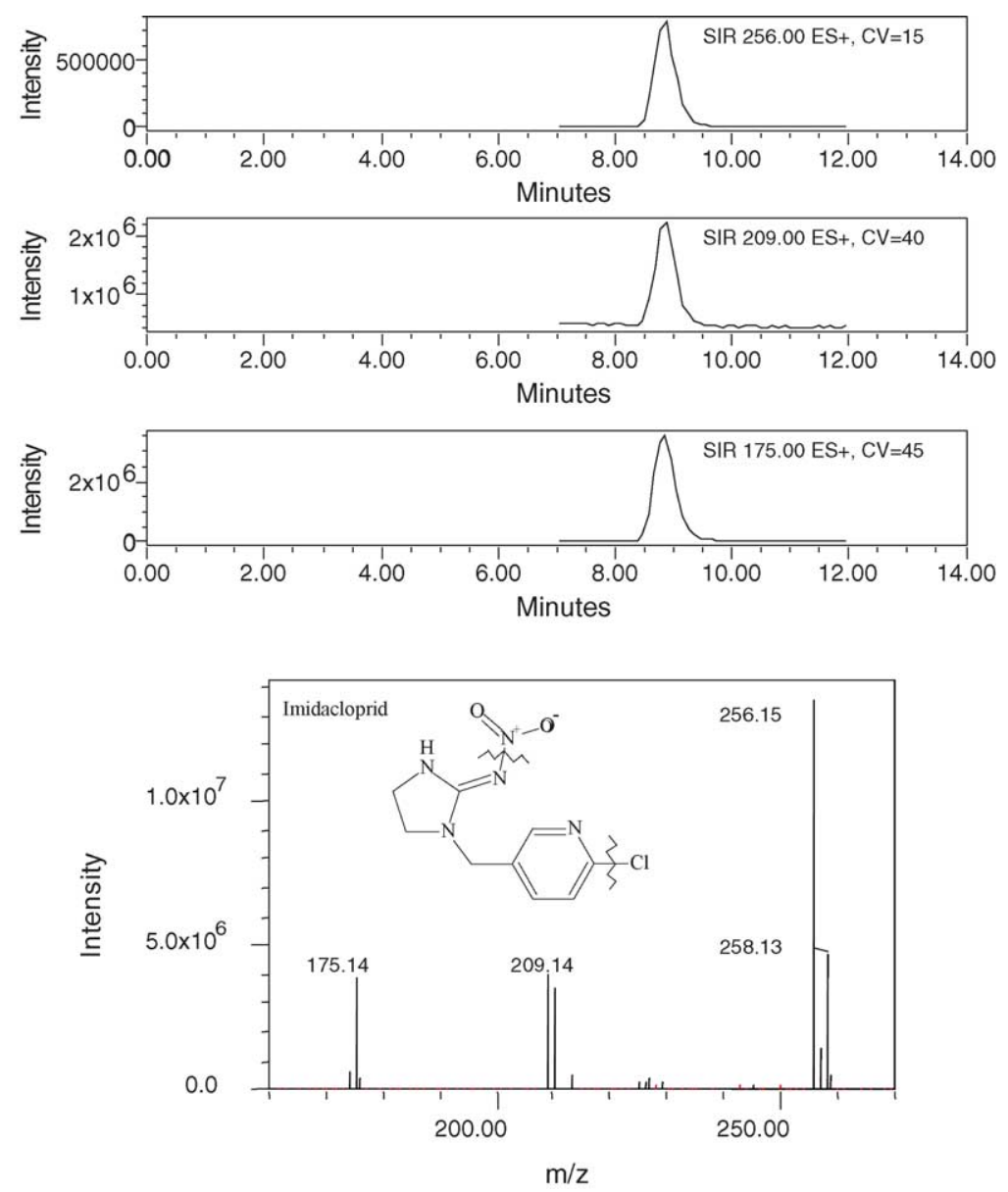

Fig. 3. SIR mass chromatograms and mass spectrum in scan mode $(\mathrm{m} / \mathrm{z}, 256)$ of imidacloprid detected in blood sample (case 1).

prid and 6-chloronicotinic acids were not detected in postmortem samples.

No published data reporting fatal cases due to imidacloprid ingestion were found, and thus results interpretation become more difficult. However, I-Wen et al. [24] described a case of an acute human intoxication with an insecticide formulation containing imidacloprid and $\mathrm{N}$-methyl pyrrolidone, as Confidor ${ }^{\mathbb{R}}$. These authors stated that most of the clinical symptoms, as minor central nervous system depression, gastrointestinal irritation and hyperglycemia, were due to $N$-methyl pyrrolidone.
The cases presented demonstrate the importance of toxicological investigation in solving cases, apparently negative in routine examinations. After the suspicion of suicidal deaths, both autopsies, as well as the analysis performed for common toxic substances, were negative. It was further investigation that identified imidacloprid as the potential causative agent in these cases. Subsequent toxicological analysis confirmed this.

The absence of other suitable causes of death (macroscopic or histological) and the positive results of toxicological findings, lead the pathologist rule that the cause of

Table 2

Ethanol and imidacloprid concentrations in post-mortem samples

\begin{tabular}{llllclcl}
\hline Cases & Analysed compounds & Blood & Urine & Kidney & Liver & Lung & Stomach contents \\
\hline Case 1 & Ethanol & $0.18 \mathrm{~g} / \mathrm{L}$ & - & - & - & - & - \\
& Imidacloprid & $12.5 \mu \mathrm{g} / \mathrm{mL}$ & Not available & $13.6 \mu \mathrm{g} / \mathrm{mL}$ & $9.9 \mu \mathrm{g} / \mathrm{mL}$ & $20.6 \mu \mathrm{g} / \mathrm{mL}$ & $70 \mathrm{mg}$ (in $200 \mathrm{~mL})$ \\
Case 2 & Ethanol & Negative & - & - & - & - & - \\
& Imidacloprid & $2.05 \mu \mathrm{g} / \mathrm{mL}$ & $0.29 \mu \mathrm{g} / \mathrm{mL}$ & $2.5 \mu \mathrm{g} / \mathrm{mL}$ & $1.01 \mu \mathrm{g} / \mathrm{mL}$ & $8.8 \mu \mathrm{g} / \mathrm{mL}$ & $37.1 \mathrm{mg}(\mathrm{in} 150 \mathrm{~mL})$ \\
\hline
\end{tabular}


death in each case was imidacloprid intoxication and the manner of death in each case was suicide.

The method was validated to detect and quantify imidacloprid in post-mortem samples. To our knowledge, this was the first time a post-mortem tissue distribution was performed for the insecticide.

\section{Acknowledgments}

The authors wish to acknowledge Dr. Peter Ohs, Head of Safe Use Assurance, Bayer CropScience, Monheim, Germany, for generously providing us 6-chloronicotinic acid and 5-hydroxyimidacloprid standards.

We also thank to the general practitioners Drs. João Melo and Celestino Reboredo who performed the autopsies and to Drs. Rita Matos and Fernanda Cavalheiro for the histological study. Special thanks go to Sónia Santos for her excellent technical toxicological assistance.

\section{References}

[1] A. Elbert, H. Overbeck, K. Iwaya, S. Tsuboi, Imidacloprid, a novel systematic nitromethylene analogue insecticide for crop protection, in: Proceedings of Brighton Crop Protection Conference, Pests and Diseases, vol. 1, Brighton, UK, 1990, pp. 21-28.

[2] L. Sheets, Imidacloprid: a neonicotinoid insecticide, second ed., in: R. Kreiger (Ed.), Handbook of Pesticide Toxicology, vol. 2, Academic Press, New York, 2001, pp. 1-8.

[3] Guia dos Produtos Fitofarmacêuticos, Ed. Direcção Geral de Protecção das culturas, 2003.

[4] C.D.S. Tomlin (Ed.), The Pesticide Manual, 11th ed., British Crop Protection Council, Surrey, UK, 1997, pp. 706-708.

[5] D.A. Schulz-Jander, J.E. Casida, Imidacloprid insecticide metabolism: human cytochrome $\mathrm{P} 450$ isozymes differ in selectivity for imidazolidine oxidation versus nitroimine reduction, Toxicol. Lett. 132 (2002) 65-70.

[6] R. Solecki, http://www.inchem.org/documents/jmpr/jmpmono/ 2001pr07.htm.

[7] J. Rouchard, et al. Imidacloprid insecticide soil metabolism in sugar beet fiels crops, Bull. Environ. Contam. 56 (1996) 29-36.

[8] S. Suchail, L. Debrauwer, L.P. Belzunces, Metabolism of imidacloprid in Apis mellifera, Pest. Manag. Sci. 60 (2004) 291-296.

[9] C. Cox, Imidacloprid, J. Pest. Reform 21 (2001) 15-21.

[10] third ed., A.C. Moffat, M.D. Osselton, B. Widdop (Eds.), Clarke's Analysis of Drugs and Poisons in Pharmaceuticals, Body Fluids and Post-Mortem Material, vol. 2, Pharmaceutical Press, London, UK, 2004, pp. 1128-1129.

[11] J.M. Bonmatin, I. Moineau, R. Charvet, C. Fleche, M.E. Colin, E.R. Bengsch, A LC/APCI-MS/MS method for analysis of imidacloprid in soils, in plants, and in pollens, Anal. Chem. 75 (2003) 2027-2033.

[12] R.S. Oliveira, et al. Sorption of imidacloprid and its metabolites on tropical soils, J. Environ. Sci. Health B35 (2000) 39-49.

[13] S. Baskaran, R.S. Kookana, R. Naidu, Determination of the insecticide imidacloprid in water and soils using high-performance liquid chromatography, J. Chromatogr. A 787 (1997) 271-275.

[14] F.J. Placke, E. Weber, Method of determining imidacloprid residues in plant materials, Pflanzenschutz-Nachrichten Bayer 46 (1993) 109-182.

[15] R. Schöning, Analytical method for determination of residues of imidacloprid, NTM 33893-5-hydroxy, and NTN 3393-olefin by HPLC with electrospray MS/MS-detection in plant and other materials, Pflanzenschutz-Nachrichten Bayer 54 (2001) 413-452.

[16] R. Schöning, R. Schmuck, Analytical determination of imidacloprid and relevant metabolite residues, Bull. Insectol. 56 (2003) 41-50.

[17] H. Obana, M. Okihashi, K. Akutsu, Y. Kitagawa, S. Hori, Determination of acetamiprid, imidacloprid, and nitenpyram residues in vegetables and fruits by high-performance liquid chromatography with diode-array detection, J. Agric. Food Chem. 50 (2002) 4464-4467.

[18] X. Pous, et al. Determination of imidacloprid, metalaxyl, myclobutanil, propham, and thiabendazole in fruits and vegetables by liquid chromatography-atmospheric pressure chemical ionization-mass spectrometry, Fresenius J. Anal. Chem. 371 (2001) 182-189.

[19] A.R. Fernandez-Alba, A. Valderde, A. Agüera, Determination of imidacloprid in vegetables by high-performance liquid chromatography with diode-array detection, J. Chromatogr. A 721 (1996) 97-105.

[20] A.R. Fernández-Alba, A. Tejedor, A. Agüera, Determination of imidacloprid and benzimidazole residues in fruits and vegetables by liquid chromatography-mass spectrometry after ethyl acetate multiresidue extraction, J. AOAC Int. 83 (2000) 748-755.

[21] C. Balasco, G. Font, Y. Picó, Comparison of microextraction procedures to determine pesticides in oranges by liquid chromatography-mass spectrometry, J. Chromatogr. A 970 (2002) 201-212.

[22] A.G. Frenich, F.J.E. González, J.L.M. Vidal, P.P. Vázques, M.M. Sánchez, Determination of imidacloprid and its metabolite 6-chloronicotinic acid in greenhouse air by high-performance liquid chromatography with diode-array detection, J. Chromatogr. A 869 (2000) 497-504.

[23] A.S. Carretero, C. Cruces-Blanco, S.P. Durán, A.F. Gutiérrez, Determination of imidacloprid and its metabolite 6-chloronicotinic acid in greenhouse air by application of micellar electrokinetic capillary chromatography with solid-phase extraction, J. Chromatogr. A 1003 (2003) 189-195.

[24] I.-W. Wu, J.-L. Lin, E.-T. Cheng, Acute poisoning with the neonicotinoid insecticide imidacloprid in $\mathrm{N}$-methyl pyrrolidone, Clin. Toxicol. 39 (2001) 617-621. 